\title{
Orthogeriatrics: much more action is needed
}

\author{
Anette Hylen Ranhoff ${ }^{1}$
}

Published online: 10 August 2020

(c) European Geriatric Medicine Society 2020
This issue of European Geriatric Medicine (EGM) has a special focus on orthogeriatrics. As a result of a call for papers together with the Journal of American Geriatrics Society (JAGS) in 2019, the EGM has received numerous manuscripts. The response on this call shows an increasing scientific and quality-improving activity in this important area of care for older people, and we are proud to present the best of the submitted papers in this issue.

Care for older people with fractures includes many aspects and a long care pathway starting with primary prevention to strengthen bone and prevent falls, via optimized acute care to efficient and successful rehabilitation. The most important aim of the care is to restore function and quality of life after fracture and prevent new fractures to happen.

To pick up the line from my editorial in 2019 [1], reading these papers rises some reflections.

First, we called for papers from Europe, Middle East, Africa, Oceania and Latin- and South America, but the far most of the submitted papers were from Western Europe. With the future perspectives on increase of the older population and then fragility fractures in all these regions, we have a job to do by transferring knowledge and support to improve fracture care in regions outside Western Europe [2].

Second, most of the submissions were about hip fracture care which is indeed the most important fragility fracture, but other fractures in older people also need action. Many older people experience fractures of the proximal humerus, which are disabling and painful and give an opportunity for recognition of osteoporosis [3], and hardly mentioned in geriatric medicine journals. Another neglected geriatric fracture is vertebral fracture [4]. Unfortunately, we received no papers worth publishing on these fractures in older people.

Third, two papers on the problems of antithrombotics and especially anticoagulants in acute hip fracture care are published $[5,6]$. They illustrate the problems with drug-related problems in hip fracture care. Introduction of new drugs to the older population can have impact on care, but also on incidence of fractures by effect on fall risk and bone health and should be carefully monitored.

Fourth, it is nice to read the papers focusing on mobilization and rehabilitation after hip fractures $[7,8]$ - this is an area where many hospitals all over the world probably have room for substantial improvement without the increase of resources and costs.

Finally, one reflection which is outside this call for papers; what is happening with a frail and high-risk patient group as the hip fracture patients when we are hit by a pandemic such as the Covid-19? Or, when we experience climate changes such as long and intense heat waves? In the future, we will probably learn more about this.

This special issue on orthogeriatrics, and the similar issue in JAGS are important contributions to the call for action from the Fragility Fracture Network (FFN) and associated organisations such as the EuGMS [2] in improving care for older people with fractures. But, far more action is needed!

Anette Hylen Ranhoff.

\section{Compliance with ethical standards}

Conflict of interest The author declares that she has no confict of interest.

Ethics approval This article does not contain any studies with human or animal subjects performed by the any of the authors.

Informed consent For this type of study, formal consent is not required.
Anette Hylen Ranhoff

anette.ranhoff@uib.no

1 University of Bergen, Bergen, Norway 


\section{References}

1. Ranhoff AH (2019) Better care for older people with hip fractures: a call for action and papers. Eur Geriatr Med. https://doi. org/10.1007/s41999-019-00194-0

2. Dreinhöfer KE, Mitchell PJ, Bégué T et al (2018) A global call to action to improve the care of people with fragility fractures. Injury 49(8):1393-1397. https://doi.org/10.1016/j.injury.2018.06.032

3. Piple A, Smith CT, Barton DW, Carmouche JJ (2020) Proximal humerus fractures in the geriatric population present an opportunity to improve recognition and treatment of osteoporosis. Geriatr Orthop Surg Rehabil 11:2151459320935103. https://doi. org/10.1177/2151459320935103

4. Sahota O, Ong T, Salem K (2018) Vertebral fragility fractures (VFF)-who, when and how to operate. Injury 49(8):1430-1435. https://doi.org/10.1016/j.injury.2018.04.018

5. Leer-Salvesen S, Dybvik E, Ranhoff AH et al (2020) Do direct oral anticoagulants (DOACs) cause delayed surgery, longer length of hospital stay, and poorer outcome for hip fracture patients? Eur Geriatr Med. https://doi.org/10.1007/s41999-020-00319-w
6. López S, da Casa C, Pablos-Hernández C et al (2020) The impact of antithrombotic therapy on surgical delay and 2-year mortality in older patients with hip fracture: a prospective observational study. Eur Geriatr Med. https://doi.org/10.1007/s41999-02000293-3

7. Ferris H, Brent L, Coughlan T (2020) Early mobilisation reduces the risk of in-hospital mortality following hip fracture. Eur Geriatr Med. https://doi.org/10.1007/s41999-020-00317-y

8. Guerzoni V, Lanzoni A, Pozzi C et al (2020) A two-year multicenter point prevalence study of older patients with hip fractures admitted to rehabilitation units in Italy. Eur Geriatr Med. https:// doi.org/10.1007/s41999-020-00363-6

Publisher's Note Springer Nature remains neutral with regard to jurisdictional claims in published maps and institutional affiliations. 